\title{
Exposição ocupacional ao cobalto: aspectos toxicológicos
}

\author{
Atecla Nunciata Lopes Alves ${ }^{1 *}$, Henrique Vicente Della Rosa ${ }^{2}$ \\ ' Serviço de Bioquímica Clínica-Setor de Toxicologia do Laboratório Central do Hospital da Clínicas da Faculdade \\ de Medicina, Universidade de São Paulo, ${ }^{2}$ Departamento de Análises Clínicas e Toxicológicas, Faculdade de \\ Ciências Farmacêuticas, Universidade de São Paulo
}

*Correspondência:

Atecla N. L. Alves

Laboratório Central HCFMUSP

Av. Dr. Enéas de Carvalho Aguiar,155

Prédio dos Ambulatórios

$2^{\circ}$ andar bloco 9

05403-010-São Paulo-SP

Brasil

E-mail: atecla@hotmail.com
O cobalto é um elemento químico, além de ser essencial, presente na vitamina $B 12$, tem sua utilização principal na indústria metalúrgica para produção de aços com características especiais de dureza e resistência. Na forma de óxidos é utilizado como catalisador na indústria química e de óleos. Na forma de sais, uma das utilizações é na indústria de cerâmica, como pigmento. Este trabalho tem por objetivo a revisão das características toxicocinéticas e toxicodinâmicas do cobalto na forma metálica, sais e óxidos. Os efeitos tóxicos observados nas exposições a diferentes compostos de cobalto são mais pronunciados nos pulmôes, na forma de asma brônquica e fibrose. A relação doseefeito e dose-resposta, bem como os valores de referência para a população sadia e não ocupacionalmente exposta, levou a ACGIH (American Conference of Governmental and Industrial Hygienists) dos Estados Unidos a propor desde 1995 a utilização de um BEI(Biological Exposure Indice) para este tipo de exposição. Apesar de o Brasil ainda não ter incluído o cobalto no Programa de Controle Médico de Saúde Ocupacional da Norma Regulamentadora-7, os estudos toxicológicos podem levar à utilização de um indicador biológico para exposições ao cobalto e seus compostos.

\author{
Unitermos: \\ - Cobalto \\ - Efeitos tóxicos \\ - Indicador biológico
}

\section{INTRODUÇÃO}

Todas as substâncias que interagem com os seres vivos, quando em excesso, podem se tornar tóxicas. $\mathrm{O}$ cobalto (Co), assim como todos os micronutrientes essenciais, apresenta duas zonas de exposição incompatíveis com a vida: tanto a deficiência como o excesso podem levar à doença ou à morte (National Research Council, 1989; Mertz, Abernathy, Olins, 1994). Ao longo de sua evolução, o homem descobre e produz novos materiais elaborados a partir de metais encontrados na natureza e, desta forma, novos riscos à saúde também são introduzidos. Durante as décadas de 60 e 70, a utilização industrial e o consumo de Co e seus compostos aumentou à taxa de 2-5\% ao ano (Elinder, Friberg, 1986).

O Brasil já começou a enfrentar este novo desafio no que diz respeito à saúde ocupacional, ou seja, faz se necessário aplicar procedimentos preventivos para os efeitos 
adversos à saúde ocasionados pelo Co e seus compostos. Em função desses fatos, cresce a importância dos conhecimentos toxicocinéticos e toxicodinâmicos.

Este trabalho tem por objetivo fornecer informações toxicológicas atualizadas do $\mathrm{Co}$, ainda não constantes dos quadros da Norma Regulamentadora 7 - Programa de Controle Médico de Saúde Ocupacional (PCMSO) (Brasil, 1999), contemplando uma das metas estabelecidas por este programa: "Para os trabalhadores expostos a agentes químicos não constantes dos quadros I e II, outros indicadores poderão ser monitorizados, dependendo de estudo prévio dos aspectos de validade toxicológica, analítica e de interpretação destes indicadores".

\section{EXPOSIÇÃO AMBIENTAL E OCUPACIONAL}

O Co é um metal branco-acinzentado com propriedades magnéticas similares ao ferro e ao níquel (Barceloux, 1999). Os principais estados de oxidação do Co são +2 e +3 , mas, na maioria dos compostos de Co disponíveis, seu estado de valência é +2 (Comission of European Communities Industrial Health and Safety, 1987)

A contaminação ambiental por um determinado metal reflete tanto fontes naturais como a atividade industrial que dele se utiliza (Klaasen, 1996). O Co é um elemento relativamente raro. Ocorre na crosta terrestre na faixa de 0,001 - 0,002\%, onde é encontrado na forma de minérios tais como a cobaltita $\left(\mathrm{CoS}_{2} \cdot \mathrm{CoAs}_{2}\right)$, linaeita $\left(\mathrm{Co}_{3} \mathrm{~S}_{4}\right)$, esmaltita $\left(\mathrm{CoAs}_{2}\right)$ e eritrita $\left(3 \mathrm{CoO} \cdot \mathrm{As}_{2} \mathrm{O}_{5} \cdot 8 \mathrm{H}_{2} \mathrm{O}\right)$ (Merck Index, 1996).

Para a população em geral, a dieta representa a principal fonte de exposição ao Co. Não existe recomendação oficial para ingestão diária de $\mathrm{Co}$, exceto no que se refere à vitamina B12 (National Research Council, 1989). As fontes de exposição ao Co através do solo, água, ar e dieta estão descritas na Tabela I.

Num estudo a respeito do impacto de atividades industriais no solo egípcio foram coletadas e dosadas amos- tras de diferentes localidades. Em solo considerado não poluído foram encontrados valores de 13,12 a $23,20 \mathrm{mg}$ de $\mathrm{Co} / \mathrm{kg}$; nos moderadamente poluídos, de 26,5 a 30,0 mg de $\mathrm{Co} / \mathrm{kg}$, e nos altamente poluídos, de 36,0 a 64,69 mg de $\mathrm{Co} / \mathrm{kg}$ (Zohny, 2002).

A principal utilização industrial do Co é na produção de ligas metálicas, nas quais a exposição ocorre durante o processo de moagem do minério, mistura do pó com os outros componentes, sinterização e posterior usinagem do aço na produção de ferramentas e peças para maquinários, tais como brocas e discos para polimento (Wehner et al., 1977; Scansetti et al., 1998). Um terço do Co é utilizado na produção de outras formas químicas, como catalisadores e pigmentos (Goyer, Cherian, 1995).

Aproximadamente $60 \%$ da produção mundial de $\mathrm{Co}$ vem das minas do Zaire e, em menor extensão, do Zâmbia, Canadá e dos Estados Unidos. O Co é produzido principalmente como subproduto da mineração de $\mathrm{Cu}$ e Ni, que usualmente contêm Co em proporção menor que $1 \%$. As ligas de Co apresentam alto ponto de fusão, dureza e resistência à oxidação (IARC, 1991). Estas propriedades dependem da composição da liga (Tabela II).

Vários sais de Co como por exemplo o acetato de cobalto II ou III, o naftenato e o octanato, são utilizados como pigmentos na indústria de vidro e de cerâmica e como agente secante de tintas e vernizes. Os óxidos de Co são utilizados como catalisadores nas indústrias química e de óleos.

O Co também é utilizado como ${ }^{60} \mathrm{Co}$ na cobaltoterapia para substituir o rádio no tratamento de alguns tipos de câncer. Na terapêutica, tem sua utilidade para tratamento da intoxicação por cianeto como CoEDTA (Comission of European Communities Industrial Health and Safety, 1987).

\section{CARACTERÍSTICAS TOXICOCINÉTICAS}

Do ponto de vista ocupacional, as principais vias de exposição são a respiratória e a dérmica. Estudos experi-

TABELA I - Fontes de exposição ambiental ao cobalto e concentrações relatadas na literatura

\begin{tabular}{lll}
\hline Fonte de exposição & Concentração & Referência \\
\hline solo & $1-40 \mathrm{mg} / \mathrm{kg}$ & $\begin{array}{l}\text { Comission of European Communities Industrial Health and } \\
\text { Safety, 1987 }\end{array}$ \\
dieta alimento & $1,7 \mathrm{a} 100 \mu \mathrm{g} / \mathrm{dia}$ & $\begin{array}{l}\text { IARC (International Agency for Research on Cancer, 1991) } \\
\text { alimento }\end{array}$ \\
$\begin{array}{l}13-36 \mu \mathrm{g} / \mathrm{dia} \\
\text { água potável }\end{array}$ & $0,1-5 \mu \mathrm{g} / \mathrm{L}$ & Fávaro et al., 1997 \\
ar & $<10 \mathrm{ng} / \mathrm{m}^{3}$ & Elinder, Friberg, 1986 \\
\hline
\end{tabular}


TABELA II - Ligas de cobalto, composição e utilização industrial (IARC, 1991)

\begin{tabular}{lll}
\hline Tipo de liga & Composição & Utilização \\
\hline Superligas resistentes à corrosão & $\begin{array}{l}\text { cobalto, cromo, níquel, tungstênio, } \\
\text { tântalo, alumínio, titânio e zircônio } \\
\text { cobalto, níquel, alumínio, } \\
\text { cobre e titânio } \\
\text { cromo e cobalto }(25-65 \%)\end{array}$ & lâminas de corte \\
aços de alta resistência & $\begin{array}{l}\text { indústria eletroeletrônica } \\
\text { peças de equipamentos que necessitam } \\
\text { de aço altamente resistente ao calor, tais } \\
\text { como turbinas de aviões }\end{array}$ \\
$\begin{array}{ll}\text { aços com propriedades especiais } \\
\begin{array}{l}\text { aço “metal duro" produzido por } \\
\text { processo de "sinterização"* }\end{array}\end{array}$ & $\begin{array}{l}\text { cromo, níquel, molibdênio e } \\
\text { pó de cobalto, ligante na produção } \\
\text { de ligas com o carbeto de } \\
\text { tungstênio e/ou titânio, tântalo, } \\
\text { nióbio e molibdênio }\end{array}$ & $\begin{array}{l}\text { lâminas de corte, brocas e } \\
\text { discos para polimento de diamantes }\end{array}$ \\
\hline
\end{tabular}

*Sinterização: é um processo de preparação de ligas metálicas, no qual a mistura de seus componentes é prensada e submetida a temperatura abaixo do seu ponto de fusão.

mentais com animais e observações na raça humana têm demonstrado que o Co é bem absorvido pelo trato gastrintestinal e pela via respiratória. A velocidade de absorção, provavelmente, é dependente da solubilidade dos compostos de Co em meio biológico (Elinder, Friberg, 1986).

\section{Absorções respiratória e gastrintestinal}

Experimentos realizados em ratos (Rhoads, Sanders, 1985) mostraram que, quando o óxido de cobalto é inalado por instilação intratraqueal $(1,5 \mu \mathrm{g} / \mathrm{g})$, fica retido no pulmão por período relativamente longo, com meiavida de, aproximadamente, 15 dias, demonstrando que a absorção pulmonar é lenta para este composto.

$\mathrm{Na}$ análise de Co em tecido pulmonar de um trabalhador exposto a Co na forma de poeira metálica encontrou-se valor de $1010 \mu \mathrm{g}$ de $\mathrm{Co} / \mathrm{kg}$ de peso úmido, sendo que, comparado com a mesma análise em pulmão de indivíduos não expostos, foi encontrada média de 5,2 $\mu \mathrm{g}$ de $\mathrm{Co} / \mathrm{kg}$ de peso úmido (Hartung, Schaller, Brand, 1982).

Não se conhecem mecanismos para controle de absorção de íons metálicos na forma livre (Tsalev, Zaprianov, 1983). A taxa de absorção oral de compostos de Co solúveis pode variar de 5 a 45\% (Morgan, 1983). As variações interindividuais são ocasionadas pelas diferentes formas químicas do Co, como também pela presença de ferro, aminoácidos e proteínas na alimentação, ou mesmo pelo estado de jejum (Tsalev, Zaprianov, 1983).

\section{Distribuição, armazenamento e excreção}

Estima-se que o organismo contenha de 0,7 a $1,1 \mathrm{mg}$ de Co, sendo que 4,4\% (0,09 a 0,22 mg) estão na forma de vitamina B12. A concentração de Co é de 1,5 a 2 vezes maior nos glóbulos vermelhos do que no plasma, no qual o Co é transportado ligado à transcobalamina (Tsalev, Zaprianov, 1983).

O Co é captado por todos os tecidos. As concentrações mais altas (aproximadamente $20 \%$ da carga total) são encontradas no fígado. Em necrópsia de fígado, os valores variaram entre 0,01 a $0,07 \mathrm{mg}$ de $\mathrm{Co} / \mathrm{kg}$ de peso úmido, a maior parte como vitamina B12. O Co é também encontrado em outros órgãos, tais como os rins, tireóide, glândulas adrenais e, em menor extensão, no músculo esquelético, coração, baço, pâncreas, cérebro e pulmão (Tsalev, Zaprianov, 1983). Não há indicações de que o Co se acumule no organismo com o passar dos anos.

Uma vez absorvido, pelo trato gastrintestinal ou respiratório, o Co é excretado principalmente pela urina, em proporção de aproximadamente $80 \%$, e em torno de $15 \%$ através das fezes (Elinder, Friberg, 1986). A eliminação urinária é caracterizada por uma fase rápida de poucos dias de duração e uma fase lenta (10\%), com meia-vida biológica de 2 a 15 anos (Tsalev, Zaprianov, 1983). Pellet et al. (1984), num estudo com trabalhadores expostos a poeiras de metal duro, observaram que, durante as primeiras 35 horas, a eliminação de Co pela urina é rápida e depois atinge um platô, que é variável de acordo com o tempo de exposição. 


\section{TOXICODINÂMICA}

Os metais têm no organismo um papel principalmente catalítico, agindo como grupo prostético em sítios ativos e/ou como cofator para metaloenzimas (Mertz, Abernathy, Olins, 1994). Assim, os alvos da ação tóxica são os processos bioquímicos que ocorrem nas células, especificamente as enzimas e/ ou membranas de células e organelas. O efeito tóxico do metal envolve, geralmente, interação entre o metal livre na forma de íon com o sítio alvo. A toxicidade é determinada pela dose nos níveis moleculares/celulares e, assim, fatores como a forma química e capacidade de ligação tornam-se críticos (Klaasen, 1996).

O mecanismo de toxicidade do Co, evidenciado experimentalmente nos processos metabólicos e em orgãos e glândulas, inclui (Tsalev, Zaprianov, 1983):

- substituição do Zn pelo Co em enzimas Zn-dependente, provocando deficiência de zinco (Marshall, Bangert, 1995);

- alterações no metabolismo de carboidratos com diminuição da utilização de glicose, na captação do oxigênio e na produção de energia;

- inativação de enzimas oxido-redutivas levando à depressão na oxidação beta de ácidos graxos de cadeia longa, na mitocôndria do miocárdio. Este mecanismo provoca danos a elementos mitocondriais e, conseqüente degeneração de sarcomas, levando a aumento da atividade de enzimas do miocárdio no soro;

- aumento da fração a-globulina e do ácido neuramínico, que é um constituinte de fração desta proteína;

- inibição da tirosina iodinase com diminuição reversível na captação de iodo pela tireóide;

- danos às células $a$ das ilhotas de Langerhans no pâncreas, provocando hiperglicemia;

- nos rins, danos às células do epitélio dos túbulos proximais, com proteinúria e glicosúria.

- no fígado, prejuízo da função hepática com infiltração gordurosa, alterações enzimáticas nos hepatócitos, resultando no aumento de enzimas hepáticas no soro.

\section{PRINCIPAIS EFEITOS TÓXICOS}

Embora historicamente a toxicologia dos metais se refira a efeitos agudos, atualmente este tipo de efeito é relativamente raro, devido aos conhecimentos de toxicidade que vão se renovando e aos critérios de prevenção adotados em saúde ocupacional (Salgado, 1996). De acordo com a atividade desenvolvida pelo trabalhador, a exposição ocupacional pode ser ao pó do metal puro e/ou a poeiras contendo óxidos ou sais de Co. A exposição ocupacional envolve principalmente o trato respiratório e a pele, sendo o órgão alvo dependente da via de exposição. Considerando as principais vias de exposição ocupacional, será abordado neste trabalho o efeito tóxico no trato respiratório, pele, sistema cardíaco e glândula tireóide, assim como o potencial carcinogênico.

\section{Trato respiratório}

De acordo especialmente com os relatos de Tolot et al. (1970) e Kusaka et al. (2001), diferentes tipos de reações podem afetar tanto o trato respiratório superior como também a árvore brônquica e o parênquima pulmonar.

$\mathrm{O}$ efeito no trato respiratório superior ocorre ou como resultado de ação irritativa de partículas contendo Co, ou por intermédio de reação mediada imunologicamente. Em trabalhadores expostos, pode-se observar inflamação da nasofaringe ou rinite alérgica.

Em alguns trabalhadores foi observado asma ocupacional devido à exposição a poeiras de metal duro, efeito decorrente da sensibilidade ao Co (Shirakawa et al., 1988; Wilk-Rivard, Szeinuk, 2001). A exposição à poeira contendo Co ocorre em todas as fases de manipulação, desde a produção do pó para ser incorporado à produção da liga até a sinterização, produção de ferramentas, e utilização das mesmas em atividades de polimento. Estes sintomas já foram observados também em trabalhadores que manipulavam óxido de cobalto (Payne, 1977). Shirakawa et al. (1988) identificaram uma IgE específica contra um complexo de Co com albumina sérica humana em trabalhadores com diagnóstico de asma brônquica, levando-se a crer que esse tipo de efeito esteja associado a uma resposta alérgica ao Co. Nestes casos, a moléstia, em geral, progride para obstrução das vias aéreas. Crises asmáticas podem ser induzidas por testes de broncoprovocação com cloreto de cobalto (Comission of European Communities Industrial Health and Safety, 1987). Testes realizados por Davison et al., em 1983, mostraram resultados positivos com relação à broncoprovocação tanto ao pó de Co puro como também na forma de metal duro, sendo considerado positivo, quando havia uma diminuição de $15 \%$ no volume expiratório forçado em 1 minuto. De acordo com o NIOSH (National Institute of Occupational Safety and Health, 1987), a irritação respiratória e os testes de função pulmonar revelam sinais de doença obstrutiva crônica e podem ser observados em concentrações de $0,06 \mathrm{mg} / \mathrm{m}^{3}$ de Co no ambiente de trabalho (Comission of European Communities Industrial Health and Safety, 1987). Estudos experimentais realizados em suínos expostos ao pó do metal puro nas concentrações de $0,1 \mathrm{mg} / \mathrm{m}^{3}$ e $1,0 \mathrm{mg} / \mathrm{m}^{3}$, comparados aos de um grupo controle, mostraram alterações nos testes de função pulmonar, 
especialmente na complacência pulmonar*, para as duas concentrações de exposição(Kerfoot, Frederick, Domejer, 1975). Na fibrose pulmonar (doença restritiva) há diminuição da complacência estática.

Exposições industriais ao Co metálico podem resultar num tipo grave de fibrose pulmonar denominada doença de metal duro ou "hard metal disease" (Hartung, Schaller, Brand, 1982; Spencer, 1985; Lison et al., 1996). Esta doença foi primeiramente descrita em trabalhadores alemães na década de 40 , sendo que, desde essa época, muitas observações têm sido feitas em países industrializados. A moléstia se inicia com tosse seca, não produtiva, que pode estar associada à insuficiência respiratória. A moléstia progride para fibrose intersticial, cujo sintoma mais significativo é dispnéia progressiva grave (Comission of European Communities Industrial Health and Safety, 1987). É bem conhecido o papel dos macrófagos nas lesões do parênquima pulmonar induzidas por vários tipos de poeiras. Estes, uma vez estimulados, podem produzir variedade de mediadores químicos, estimulando a proliferação de fibroblastos (Lison, Lauwerys, 1990). Em alguns relatos de trabalhadores expostos à poeira de Co na forma de liga com carbeto de tungstênio, a exaustão na área de manipulação da liga refletiu em melhora moderada nos testes de função pulmonar, comparados com a situação sem exaustão. Esta ocorria mesmo após o estabelecimento da fase fibrótica, sem que os valores esperados para os testes retornassem à normalidade (Demets et al., 1984). Por outro lado, existem relatos de instalação de fibrose irreversível progressiva, levando à morte mesmo após a retirada do trabalhador do ambiente de exposição (Forrester, Skerker, Nemiroff, 1978).

A hipersuscetibilidade individual desempenha, provavelmente, papel importante, uma vez que apenas pequena porcentagem de trabalhadores expostos ao Co desenvolve fibrose intersticial. Em alguns estudos, verificou-se não existir boa correlação entre o estabelecimento da fibrose e o tempo de exposição (Demets et al., 1984). O fato de os pulmões fibróticos conterem pequenas quantidades de Co pode ser explicado pela alta solubilidade desse metal nos fluidos biológicos, até mais que em solução fisiológica, causando, assim, rápida remoção deste do tecido pulmonar (Hartung, Schaller, Brand, 1982). Alguns dos fatores responsáveis pela suscetibilidade na indução de moléstia pulmonar intersticial são genéticos como por exemplo a expressão de enzimas de biotransformação pulmonares, o sistema de proteção celular a agentes oxidantes e as diferenças individuais na resposta imune (Nemery et al, 2001)

Num estudo epidemiológico realizado em trabalhadores que produziam Co na forma de óxidos, sais e metal puro, não se observaram alterações no parênquima pulmonar comparativamente a um grupo controle (Morgan, 1983; Swennen et al., 1993).

Ainda com relação às lesões parenquimatosas e à interação com o carbeto de tungstênio, merece atenção o fato de que o indivíduo ocupacionalmente exposto ao $\mathrm{Co}$ poder também estar exposto a outras partículas. Lison e Lauwerys (1990), através de estudos de toxicidade "in vitro" com macrófagos peritoneais e alveolares de ratos, demonstraram claramente que a reatividade da mistura carbeto de tungstênio e Co é diferente daquela observada com o pó de Co puro e o carbeto de tungstênio isoladamente. Testados separadamente, tanto o carbeto de tungstênio como o pó de Co puro provocam alterações leves na viabilidade celular, monitorizada pela liberação da enzima desidrogenase láctica (DHL), e alterações morfológicas dos macrófagos. Neste mesmo estudo verificou-se que a captação de partículas de Co pelos macrófagos aumenta na presença do carbeto de tungstênio. Estes dados concordam com estudos realizados em ratos (Lasfargues et al., 1992), nos quais foi verificado que a instilação da mistura de Co com carbeto de tungstênio $(1,0 \mathrm{mg}$ de $\mathrm{Co} /$ $16,67 \mathrm{mg}$ carbeto de tungstênio/100 g de peso corpóreo) provocava alveolite grave e edema pulmonar fatal. Em contrapartida, a aplicação de dose equivalente de pó de Co puro causava efeito inflamatório moderado.

Tem-se discutido, também, que a toxicidade do Co, dose-dependente da concentração presente no ambiente de trabalho, pode estar relacionada à forma iônica ou molecular do Co (Demets et al., 1984; Sjogren et al., 1980).

Alguns trabalhos sugerem que os níveis aceitáveis de exposição deveriam variar, dependendo se a exposição for decorrente do metal puro ou em combinação com outras substâncias como o carbeto de tungstênio (Lasfargues et al., 1992; Lison, Lauwerys, 1990). A exposição simultânea a outros agentes tóxicos como o Ni, experimentalmente, demonstrou efeito tóxico sinérgico em cultura de células epiteliais alveolares (Cross, Ramachandran, Wattenberg, 2001)

Recentemente, estudos em macrófagos alveolares de ratos têm sido desenvolvidos com o intuito de se encontrar marcadores para o efeito citotóxico das partículas de Co metálico isoladas ou na mistura com carbeto de

* Complacência é um teste de função pulmonar, cujo objetivo é mensurar alterações no volume pulmonar causadas por pressão intra-alveolar, avaliando a elasticidade e a capacidade de distensão dos pulmões e tórax. 
tungstênio. A alteração da atividade da enzima hexose monofosfato foi testada como um marcador deste efeito, apesar de ainda não ter sido encontrada correlação desta ativação com o efeito citotóxico (Hoet et al., 2002).

\section{Pele}

Em uma indústria de manufatura de carbetos, cujos materiais utilizados incluíam Co metálico, observou-se aumento progressivo dos casos de dermatite, sugerindo que o Co pode provocar eczema e urticária (Schwartz et al., 1945). Reações dérmicas também já foram observadas em trabalhadores que produziam sais e óxidos de Co (Swennen et al., 1993). Estas reações se assemelham a dermatite alérgica de contacto caracterizada por pápulas eritematosas, que se assemelham muito àquelas provocadas pelo níquel. Nestes casos, testes de sensibilização dérmica com cloreto de cobalto a $1 \%$ mostraram reações positivas. Reações cruzadas com o níquel parecem freqüentes. Observações clínicas sugerem que trabalhadores expostos a metais duros com sensibilidade simultânea ao $\mathrm{Ni}$ e Co apresentam eczema muito mais grave do que aqueles com sensibilidade ao $\mathrm{Ni}$ ou Co isoladamente (Comission of European Communities Industrial Health and Safety, 1987).

\section{Sistema cardíaco e glândula tireóide}

Exposições ao Co por via oral e pulmonar podem produzir lesões no miocárdio. Estudos a respeito destes efeitos foram realizados após surtos endêmicos de cardiomiopatia degenerativa fatal observada em consumidores habituais de cerveja, após a introdução de cloreto e/ ou sulfato de Co como estabilizadores de espuma na cerveja de alguns países (Elinder, Friberg, 1986).

Estudos experimentais, em que suínos foram submetidos a concentrações de $0,1 \mathrm{mg} / \mathrm{m}^{3}$ e $1,0 \mathrm{mg} / \mathrm{m}^{3}$ de poeiras de Co metal puro no ar ambiente (6 horas/dia, 5 dias por semana, 6 meses), mostraram alterações no eletrocardiograma(ECG), indicando algum tipo de anormalidade funcional (Kerfoot, Fredrick, Domejer, 1975). Mais recentemente, estudos realizados em animais com administração diária de Co na alimentação mostraram que após 16-24 semanas havia aumento significativo na concentração de Co no miocárdio em relação a um grupo controle que não havia ingerido Co (Haga et al., 1996). Diferentes casos de miocardiopatia foram associados à exposição industrial:

a) um indivíduo que foi a óbito por choque cardíaco durante uma cirurgia trabalhava em atividade que envolvia manipulação do pó do Co na forma metálica. Du- rante a necrópsia, realizou-se estudo microscópico do tecido do miocárdio, revelando fibrose extensa e difusa. Uma amostra deste tecido foi analisada para o Co e revelou concentrações de $7 \mu \mathrm{g} / \mathrm{g}$, quando comparada a um grupo controle no qual foram encontrados níveis de Co de 0,1-0,4 $\mu \mathrm{g} / \mathrm{g}$ de miocárdio (Kennedy, King, Dornan, 1981);

b) o estudo microscópico do tecido do miocárdio necropsiado de um indivíduo que havia sido submetido à exposição a pó de Co metálico por 4 anos revelou semelhança àquele efetuado entre os consumidores de cerveja. Estes apresentaram cardiomiopatia fatal, após consumo de cerveja com sulfato de cobalto (Barborik, Dusek, 1972).

Em uma indústria que produzia sais, óxidos e pó de Co metálico observaram-se, em alguns trabalhadores, alterações no metabolismo tireoideano com aumento de TSH (hormônio tireoideano) e diminuição de $\mathrm{T}_{3}$ (triiodotironina) e $\mathrm{T}_{4}$ (tetraiodotironina) (Sampson, 1988).

\section{CARCINOGENICIDADE E GENOTOXICIDADE}

Diversos experimentos realizados em animais de laboratório mostraram que injeções intramusculares, subcutâneas ou intraperitoneais, únicas ou repetidas, de pó de Co ou compostos de Co, podem produzir tumores no local da injeção (Leonard, Lauwerys, 1990). Por outro lado, Steinhoff e Mohr (1991) verificaram que a administração de óxido de cobalto (II) em ratos induzia tumores de pulmão em apenas alguns animais. Alguns autores acreditam haver evidências suficientes da carcinogenicidade do pó do metal e óxido de cobalto II em animais experimentais (Goyer, Cherian, 1995)

Em vários estudos epidemiológicos realizados com trabalhadores expostos ao Co nas suas diferentes formas foi constatado aumento no número de casos de câncer de pulmão. A autenticidade da origem ocupacional da doença não pôde ser estabelecida devido ao número muito baixo de casos, além de estar associado ao tabagismo e à exposição simultânea a arsênio e níquel (Mur et al., 1987; NIOSH, 1987; Comission of European Communities Industrial Health and Safety, 1987; Hogsted, Alexandersson, 1990). Moulin et al. (1998) e Wild et al. (2000) realizaram estudos epidemiológicos que dão suporte à hipótese de que em indústrias de "metal duro" há aumento na mortalidade de câncer pulmonar, quando há exposição simultaneamente ao Co e carbeto de tungstênio. Em estudos de genotoxicidade em trabalhadores de refinarias de Co e metal duro, foram utilizados biomarcadores de efeito como a dosagem de 8hidroxiguanosina na urina, que reflete dano inicial ao DNA. Os estudos revelaram aumento de 8-hidroxiguanosina ape- 
nas em trabalhadores expostos ao Co, que possuíam o hábito de fumar, levando à hipótese que o risco de câncer pulmonar seria maior para este grupo (De Boeck et al., 2000). A propriedade de potencializar a mutagenicidade e carcinogenicidade de agentes genotóxicos é uma característica do Co (Beyersmann, 2002).

O papel dos metais no mecanismo de carcinogênese consiste na reação com vários compostos endógenos, tais como peróxido de hidrogênio, radicais sulfito e glutationa, produzindo espécies ativas e reativas, causando alterações no DNA, consideradas mutagênicas (Goyer, Cherian, 1995; Bal, Kasprzak, 2002). Os efeitos mutagênicos também podem ser explicados pelas alterações provocadas nos mecanismos de reparo do DNA ainda não esclarecidas completamente (Hartwig, Schwerdtle, 2002)

Segundo o IARC, o Co e os compostos de Co são considerados potencialmente carcinógenos ao homem (grupo 2B), pois montraram fortes evidências de carcinogenicidade em animais experimentais.

Com o intuito de atualizar os dados de carcinogenicidade e genotoxicidade dos compostos de Co, Lison et al. (2001), em artigo de revisão, concluiram que:

- há evidências de que cátions de Co (II) solúveis exercem atividade genotóxica e carcinogênica in vitro e in vivo em sistemas experimentais, mas a evidência na espécie humana não é conclusiva;

- dados experimentais indicam genotoxicidade potencial em linfócitos humanos in vitro, sem evidência de potencial carcinogênico;

- há evidências que as partículas de "metal duro" exercem atividade genotóxica e carcinogênica in vitro e em estudos na espécie humana;

- as informações relativas aos óxidos de Co e outros compostos não são ainda suficientes.

\section{MONITORIZAÇÃO BIOLÓGICA E INDICADORES BIOLÓGICOS}

A implantação de programas de monitorização biológica tem como objetivo auxiliar na tomada de decisões relativas à prevenção de efeitos nocivos na exposição ocupacional (Della Rosa, Siqueira, Colacioppo, 1996). Para que se estabeleça um programa de monitorização biológica é necessário: a existência de um indicador biológico, conhecimento da toxicocinética, existência de um método analítico adequado, relação dose-efeito, dose-resposta e estudos conclusivos sobre valores de referência. Baseado nestes estudos a ACGIH, desde 1995, faz recomendações para exposição ocupacional ao Co e utiliza o termo TLVTWA (Thereshold Limit Value) e BEI (Biological Exposure Indice), que correspondem, na legislação brasileira (Brasil, 1999), respectivamente, aos LTs (Limites de Tolerância) e IBMP (Índice Biológico Máximo Permitido) para exposição a agentes químicos no ambiente de trabalho.

A dosagem de Co urinário é o indicador biológico mais recomendado para monitorar a exposição de Co no ambiente de trabalho (Linnainmaa, Kiilunen, 1997). A ACGIH (American Conference of Governmental and Industrial Hygyenists, 2002), recomenda TLV-TWA no ar ambiente de até $0,02 \mathrm{mg} / \mathrm{m}^{3}$. Aspectos preventivos, tais como a utilização de sistemas fechados com exaustão, são recomendáveis na exposição ocupacional ao Co (Linnainmaa, Kangas, Kalliokoski, 1996). Na Tabela III encontram-se os indicadores recomendados, o valor de referência na população não-exposta, o horário da coleta e o BEI.

É importante ressaltar que o efeito alérgico não é dose-dependente e concentrações muito baixas no ar ambiente podem causar respostas asmáticas (Wilk-Rivard, Szeinuk, 2001). Portanto, para este tipo de situação, o trabalhador exposto não poderia se beneficiar da medida de um indicador biológico para monitorizar a exposição ao Co. Há necessidade de pesquisas futuras no sentido de se desenvolver marcadores biológicos de respostas imunológicas induzidas por metais bem como o estudo da suscetibilidade genética para este tipo de exposição (Lelleher, Pacheco, Newman, 2000)

Pela revisão realizada, verificou-se a existência de informações toxicológicas necessárias e suficientes que justificam a introdução de indicadores biológicos para a exposição ao cobalto e seus compostos solúveis, no PCMSO .

Tabela III - Recomendações da ACGIH para monitorização biológica da exposição ao Co (ACGIH, 2002) e valores de referência para a população não exposta (Minoia et al. 1990)

\begin{tabular}{ccccc}
\hline Agente Químico & Indicador Biológico & Valor de Referência & Horário de coleta & BEI \\
\hline Co & Co urina & $0,18-0,96 \mu \mathrm{g} / \mathrm{L}$ & $\begin{array}{c}\text { Final da jornada e } \\
\text { da semana }\end{array}$ & $\begin{array}{c}15 \mu \mathrm{g} / \mathrm{g} \text { de } \\
\text { creatinina }\end{array}$ \\
& Co sangue & $0,01-0,91 \mu \mathrm{g} / \mathrm{L}$ & Final da jornada & $1 \mu \mathrm{g} / \mathrm{L}$ \\
\hline
\end{tabular}




\section{ABSTRACT}

\section{Cobalt exposure: toxicological aspects}

Cobalt is a chemical element that, besides its essentiality as a vitamin B12 component, has its main use in metallurgy to produce steel with special features of hardness and resistance. Oxides have been used as catalists for chemical and oil industry, in salts forms, as pigments in ceramics plants. This work has the purpose of a toxicocinetic and toxicodinamic review of exposure to cobalt in metal, salt and oxide forms. The toxic effects observed in exposure to different cobalt compounds are more pronunciated in pulmonary level, in bronchial and fibrotic forms. The toxic effects observed in the exposure to different cobalt compounds, the dose-effect relationship and dose-response, and the reference values in health and non-exposed population, have brought ACGIH (American Conference of Governmental and Industrial Hygienists) of the United States to propose since 1995 a BEI (Biological Exposure Indice) to this kind of exposure. Although Brazil has not included cobalt in the PCMSO (Programa de Controle Médico de Saúde Ocupacional), the toxicological studies can lead to the use of a biological indicator to cobalt and respective compound exposure.

UNITERMOS: Cobalt. Toxic effects. Biological indicators

\section{AGRADECIMENTOS}

À Diretoria do Laboratório Central e do Serviço de Bioquímica Clínica do HCFMUSP, por ter permitido a realização do trabalho.

\section{REFERÊNCIAS BIBLIOGRÁFICAS}

AMERICAN CONFERENCE OF GOVERNMENTAL AND INDUSTRIAL HYGIENISTS. Limites de Exposição (TLVS) para substâncias químicas e agentes físicos e Índices Biológicos de Exposição (BEIs). Cincinnati: ACGIH, 2002.

BAL, W.; KASPRZAK, K. S. Induction of oxidative DNA damage by carcinogenic metals. Toxicol. Lett., Shanon, v.127, p. 55-62, 2002.
BARBORIK, M.; DUSEK, J. Cardiomyiopathy accompaning industrial cobalt exposure. Br. Heart J., London, v.34, p.113-116, 1972. Apud: DELLA ROSA, H. V. Exposição ao Co, riscos à saúde. São Paulo: Sindicato das Indústrias de Produtos Químicos para fins Industriais e Petroquímicos no Estado de São Paulo, 1996. n.p. [Apostila].

BARCELOUX, D. G. Cobalt. J. Toxicol. Clin. Toxicol., New York, v.37, p. 201-206, 1999.

BEYERSMANN, D. Effects of carcinogenic metals on gene expression. Toxicol. Lett., Shanon, v.127, p. 63-68, 2002.

BRASIL. Portaria n ${ }^{\circ} 8$ de 8-5-1996. Segurança e Medicina do Trabalho. Normas regulamentadoras. NR 7-Programa de Controle Médico de saúde Ocupacional. In: MANUAIS DE LEGISLAÇÃO ATLAS SEGURANÇA E MEDICINA DO TRABALHO. São Paulo: Atlas, 1999. p.86-92.

COMMISSION OF EUROPEAN COMMUNITIES INDUSTRIAL HEALTH AND SAFETY. Biological indicators for the assessment of human exposure to industrial chemicals: cobalt s. n. t., 1987. p.51-61. [Fotocópia]

CROSS, D. P.; RAMACHANDRAN, G.; WATTENBERG, E. Mixtures of nickel and cobalt chlorides induce synergistic cytotoxic effercts: implications for inhalation exposure modeling. Ann. Occup. Hyg., Oxford, v.45, n.5, p. 409-418, 2001.

DAVISON, A. G.; HASLAM, P. L.; CORRIN, B.; COUTTS, I. I.; DEWAR, A.; RIDING, W. D.; STUDY, P. R.; NEWMAN-TAYLOR, A. J. Interstitial lung disease and asthma in hard-metal workers: bronchoalveolar lavage, ultrastructural, and analytical findings and results of bronchial provocation tests. Thorax, London, v.38, p.119$128,1983$.

De BOECK, M.; LARDAU, S.; BUCHET, J. P.; KIRSCHVOLDERS, M.; LISON, D. Absence of significant genotoxicity in lymphocytes and urine from workers exposed to moderate levels of cobalt-containing dust: A cross-sectional study. Environ. Mol. Mutagen., New York, v.36, p.151-160, 2000. 
DELLA ROSA, H. V.; SIQUEIRA, M. E. P. B.; COLACIOPPO, S. Monitorização ambiental e biológica. In: OGA, S. Fundamentos de toxicologia. São Paulo: Ateneu,1996. cap 3.1, p.137-151.

DEMETS, M.; CHEYSENS, B.; NAGELS, J.; VERBEKEN, E.; LAUWERYS, J.; VAN DEN ECKOUT, A.; LAHAYE, D.; GYSELEN, A. Cobalt lung in diamond polishers. Am. Rev. Respir. Dis., New York, v.130, p.130-135, 1984. Apud: DELLA ROSA, H. V. Exposição ao Co, riscos à saúde. São Paulo: Sindicato das Indústrias de Produtos Químicos para fins Industriais e Petroquímicos no Estado de São Paulo, 1996. n.p. [Apostila].

ELINDER, C. G.; FRIBERG, I. Cobalt. In: Handbook on the toxicology of metals 2.ed. Amsterdam: Elsevier, 1986. cap.9, p.68-78. [VII: specific metals]

FÁVARO, D. I. T. HUI, M. L. T.; COZZOLINO, S. M. F.; MAIHARA, V. A.; ARMELIN, M. J. A.; VASCONCELLOS, M. B.; YUYAMA, L. K.; BOAVENTURA, G. T.; TRAMONTE, V. L. Determination of various nutrients and toxic elements in different Brazilian regional diets by neutron activation analysis. J. Trace Elem. Med. Biol., Jena, v.11, p.129-136, 1997.

FORRESTER, M. E.; SKERKER, L. B.; NEMIROFF, M. J. Hard metal pneumoconiosis: another cause of diffuse interstitial fibrosis. Radiology, Syracuse, v.128, p.609612,1978 .

GOYER, A. R.; CHERIAN, G. M. Toxicology of metals. Heidelberg: Springer, 1995. p.358-360.

HAGA, Y.; CLYNE, N.; HATORI, N.; HOFFMAN-BANG, C.; PEHERSSON, S. K.; RYDEN, L. Impaired myocardial function following chronic cobalt exposure in an isolated heart model. Trace Elem. Electrolytes, Muenchen-Deisenhofen, v. 13, p. 69-74, 1996.

HARTUNG, M.; SCHALLER, K. H.; BRAND, E. On the question of the pathogenic importance of cobalt for hard metal fibrosis of the lung. Int. Arch. Occup. Environ. Health, Berlin, v.50, p.53-57, 1982.

HARTWIG, A.; SCHWERDTLE, T. Interactions by carcinogenic metal compounds with DNA repair processes: toxicological implications, Toxicol. Lett., Shanon, v.127, p. 47-54, 2002.
HOET, P. H.; ROESEMS, G.; DEMEDTS, M. G.; NEMERY, B. Activation of the hexose monophosphate shunt in rat type II pneumocytes as an early marker of oxidative stress caused by cobalt particles. Arch. Toxicol., Berlin, v.76, p.1-7, 2002.

HOGSTED, C.; ALEXANDERSSON, R. Dodsorsaker hos hardmetallarbetare Arbete Hälsa, 21 (26 p.), 1990. Apud: DELLA ROSA, H. V. Exposição ao Co, riscos à saúde. São Paulo: Sindicato das Indústrias de Produtos Químicos para fins Industriais e Petroquímicos no Estado de São Paulo, 1996. n.p. [Apostila].

INTERNATIONAL AGENCY FOR RESEARCH ON CANCER - IARC. Monographs on the evaluation of carcinogenic risks to humans. Chlorinated drinking water, chlorinated by products, some other halogenated compounds, cobalt and cobalt compounds. Lyon, v.52, 1991.

KELLEHER, P.; PACHECO, K.; NEWMAN, L. S. Inorganic dust pneumonias: the metal-related parenchymal disorders. Environ. Health Perspectives, Washington, v. 108, n.4, p. 685-696, 2000.

KENNEDY, A.; KING, R.; DORNAN, J. D. Fatal myocardial disease associated with industrial exposure to cobalt. Lancet, London, v.21, p.412-414, 1981.

KERFOOT, F. J.; FREDRICK, W. G.; DOMEJER, E. Cobalt metal inhalation studies on miniature swine. Am. Ind. Hyg. Assoc. J., Chicago, v.36, p.17-25, 1975.

KLAASSEN, C. D., ed. Casarett and Doulls Toxicology. 5.ed. New York: McGraw-Hill, 1996. p.443-60, 691-693, 714-715.

KUSAKA, y.; SATO, K.; SUGANUMA, N.; HOSODA, Y. Metal-Induced lung disease: lessons from Japan's experience, J. Occup. Health, Tokyo, v. 43, p. 1-23, 2001.

LAHAYE, D.; DEMEDTS, M.; VANDEN OEVER, R.; ROOSELS, D. Lung diseases among diamond polishers due to cobalt? Lancet, London,n.8369, p.156-157, 1984. [Letter].

LASFARGUES, G.; LISON, D.; MALDAGUE, P.; LAUWERYS, R. Comparative study of acute lung toxicology of pure cobalt powder and cobalt-tungsten carbide mixture in rat. Toxicol. Appl. Pharmacol., Orlando, v.112, p.41-50, 1992. 
LEONARD, A.; LAUWERYS, R. Mutagenicity, carcinogecity and teratogenicy of cobalt metal and cobalt compounds. Mutat. Res., Amsterdam, v.239, p.17-27, 1990.

LINNAINMAA, M.; KANGAS, J.; KALLIOKOSKI, P. Exposure to airbone metals in the manufacture and maintenance of hard metal and stellite blades, Am. Ind. Hyg. Assoc. J., Chicago, v. 57, p. 196-201, 1996.

LINNAINMAA, M.; KIILUNEN, M. Urinary cobalt as a measure of exposure in the wet sharpening of hard metal and stellite blades. Int. Arch. Occup. Environ. Health, Berlin, v.69, p.193-200, 1997.

LISON, D.; DE BOECK, M.; VEROUGSTRAETE, V.; KIRSCH-VOLDERS, M. Update on the genotoxicity and carcinogenicity of cobalt compounds. Occup. Environ. Med., London, v.58, p.619-625, 2001.

LISON, D.; LAUWERYS, R. In vitro cytotoxic effects of cobalt-containing dusts of mouse peritoneal and rat alveolar macrophages. Environ. Res., New York, v.52, p.187-198, 1990.

LISON, D.; LAUWERYS, R.; DEMEDTS, M.; NEMERY, B. Experimental research into the pathogenesis of cobalt metal lung disease. Eur. Resp. J., Sheffield, v.9, p.10241028, 1996.

MARSHALL, J. W.; BANGERT, S.K. Clinical biochemistry metabolic and clinical aspects. New York: Churchill Livingstone, 1995. p.182-183.

MERCK INDEX: an encyclopedia of chemicals, drugs and biologicals. 12.ed. Whitehouse Station: Merck, 1996. p.2488-2504.

MERTZ, W.; ABERNATHY, C. O.; OLINS, S. S.; eds. Risk assessment of essential elements. Washington: ILSI Press, 1994. p.13-15, 48-49.

MINOIA, C.; SABBIONI, E.; APOSTOLI, P.; PIETRA, R.; POZZOLI, L.; GALLORINI, M.; NICOLAU, G.; ALESSIO, G.; CAPODAGLIO, E. Trace element reference values in tissues from inhabitants of the european community. A study of 46 elements in urine, blood and serum of Italian subjects. Sci. Total Environ., Amsterdam, v.95, p.89-105, 1990.
MORGAN, L. G. A study into the health and mortality of men exposed to cobalt and oxides. J. Soc. Occup. Med., London, v.33, p.181-186, 1983.

MOULIN, J. J.; WILD, P.; ROMAZINI, S.; LASFARGUES, G.; PELTIER, A., BOZEC, C.; DEGUERRY, P.; PELLET, F.; PERDRIX, A. Lung cancer risk in hardmetal workers. Am. J. Epidemiol., Baltimore, v.148, p.241-248, 1998.

MUR, J. M.; MOULIN, J. J.; CHARRUYER-SEINERRA, M. P.; LAFITTE, J. A cohort mortality study among cobalt and sodium workers in an eletrochemical plant. Am. J. Ind. Med., New York, v.11, p.75-81, 1987.

NATIONAL INSTITUTE OF OCCUPATIONAL SAFETY AND HEALTH (NIOSH), 1981. Criteria for controlling occupational exposure to cobalt-National Hazard Assessment, DHHS - Publication. Washington D.C. Superintendent of Documents. US Government Print Office, 1981. no.82-107. p. 95. Apud: COMMISSION OF EUROPEAN COMMUNITIES INDUSTRIAL HEALTH AND SAFETY. Biological indicators for the assessment of human exposure to industrial chemicals: cobalt s. n. t., 1987. p.51-61. [ Fotocópia]

NATIONAL RESEARCH COUNCIL (U.S.) Subcommittee on the Tenth Edition of the RDAs. Recommended dietary allowances. 10.ed. Washington: National Academy Press, 1989. p.267-268.

NEMERY, B.; BAST, A.; BEHR, J.; BORM, P. J. A.; BOURKE, S. J.; CAMUS, PH.; DE VUYST, P.; JANSEN, H. M.; KINNULA, V. L.; LISON, D.; PELKONEN, O.; SALTINI, C. Instersticial lung disease induced by exogenous agents: factors governing susceptibility, Eur. Resp. J., Sheffield, v. 18, p. 30-42, 2001.

PAYNE, L. R. The hazards of cobalt. J. Soc. Occup. Med., London, v.27, p.20-25, 1977.

PELLET, F.; PEDRIX, A.;VINCENT, M.; MALLION, J. M. Dosage biologique du cobalt urinaire. Arch. Mal. Prof., Paris, v.45, p.81-85, 1984.

RHOADS, K.; SANDERS, C. L. Lung clearance, translocation and acute toxicity of arsenic, berillium, cadmium, cobalt, lead, selenium and ytterbium oxides following deposition in rat lung. Environ. Res., New York, v.36, p.359-378, 1985. 
SALGADO, P. E. T. Toxicologia dos metais. In: OGA, S. Fundamentos de toxicologia. São Paulo: Ateneu, 1996. cap 3.2, p.154.

SAMPSON, B. Determination of cobalt in plasma and urine by electrothermal atomisation atomic absorption spectrometry using palladium matrix modification. $J$. Anal. At. Spectrom., London, v.3, p.465-469, 1988.

SCANSETTI, G.; MAINA, G.; BOTTA, GC.; BAMBACE, P.; SPINELLI, P. Exposure to cobalt and nickel in the hard-metal production industry, Int. Arch. Occup. Environ. Health, Berlin, v.71, p.60-63, 1998.

SCHWARTZ, L.; PECK, S. M.; BLAIR, K. E.; MARKUSON, E. Allergic dermatitis due to metallic cobalt. J. Allergy, St. Louis, v.16, p.51-53, 1945. Apud: DELLA ROSA, H. V. Exposição ao Co, riscos à saúde. São Paulo: Sindicato das Indústrias de Produtos Químicos para fins Industriais e Petroquímicos no Estado de São Paulo, 1996. n.p. [Apostila].

SHIRAKAWA, T.; KUSAKA, Y.; FUJIMURA, N.; GOTO, S.; MORIMOTO, K. The existence of specific antibodies to cobalt in hard metal asthma. Clin. Allergy, Oxford, v.18, p.451-460, 1988.

SJÖGREN, I.; HILLERDAL, G.; ANDERSSON, A.; ZETTERSTROM, O. Hard metal lung disease: importance of metals in coolants. Thorax, London, v.35, p.653-659, 1980.

SPENCER, H. Pathology of the lung. 4.ed. Oxford: Pergamon Press, 1985. v.1, p.481-482.

STEINHOFF, D.; MOHR, U. On the question of a carcinogenic action of cobalt containing compounds. Exp. Pathol., Jena, v.41, p.169-174, 1991.
SWENNEN, B.; BUCHET, J-P.; STÁNESCU, D.; LISON, D.; LAUWERYS, R. Epidemiologic survey on workers exposed to cobalt oxides, cobalt salts and cobalt metal. $\mathrm{Br}$. J. Ind. Med., London, v.50, p.835-842, 1993.

TOLOT, F.; GIRARD, R.; DORTIT, G.; TABOURIN, G.; GALY, P.; BOURRET. J. Manifestations pulmonaires des metaux durs. Troubles irritatifes (enquête et observations cliniques). Arch. Mal. Prof., Paris, v.31, p.453-470, 1970.

TSALEV, D. L.; ZAPRIANOV, Z. K. Atomic absorption spectrometry in occupational and environmental health practice. Boca Raton: CRC Press, 1983. v.1 p.117-121.

WEHNER, A. P.; BUSCH, R. H.; OLSEN, R. J.; CRAIG, D. K. Chronic inhalation of cobalt oxide and cigarette smoke by hamsters. Am. Ind. Hyg. Assoc. J., Chicago, v.38, p.338-346, 1977.

WILD, P.; PERDRIX, A.; ROMAZINI, S.; MOULIN, J.; PELLET, F. Lung cancer mortality in a site producing hard metals. Occup. Environ. Med., London, v.57, p.568573,2000 .

WILK-RIVARD, E.; SZEINUK, J. Occupational asthma with paroxyismal atrial fibrillation in a diamond polisher. Environ. Health Perspectives, Washington, v.109, p. 1303-1306, 2001.

ZOHNY,E. A. Cobalt in alluvial Egyptian soils as affected by industrial activities, J. Environ. Sci., Beijing, v.14, p. 34$38,2002$.

Recebido para publicação em 20 de junho de 2002. 